\title{
Perioperative Serum Carcinoembryonic Antigen Ratio Is a Prognostic Indicator in Patients With Stage II Colorectal
}

\section{Cancer}

Jinsun Woo, Jungbin Kim, Inseok Park, Hyunjin Cho, Geumhee Gwak, Keun Ho Yang, Byung-Noe Bae, Ki Hwan Kim

Department of Surgery, Inje University Sanggye Paik Hospital, Inje University College of Medicine, Seoul, Korea

Purpose: The aim of this study was to evaluate whether the perioperative carcinoembryonic antigen (CEA) ratio could be used as a determinant for adjuvant therapy after curative surgery in stage II colorectal cancer.

Methods: Data for 119 patients with stage II colorectal cancer who underwent radical surgery between 2010 and 2013 were collected. The perioperative CEA ratio was defined as the postoperative/preoperative serum CEA level, and the patients were grouped according to their perioperative CEA ratios: high ratio $(\geq 0.5)$ and low ratio $(<0.5)$. Overall survival rates were calculated, and their prognostic significances were analyzed.

Results: The overall survival rates of the high and the low perioperative CEA groups were $68.2 \%$ and $86.8 \%$, respectively $(\mathrm{P}=0.033)$. In patients with normal preoperative CEA levels $(<5 \mathrm{ng} / \mathrm{mL})$, the high perioperative CEA ratio group showed a worse survival rate than the low perioperative CEA ratio group $(71.7 \%$ vs. $100.0 \%, P=0.007)$. In patients with high preoperative CEA levels ( $\geq 5 \mathrm{ng} / \mathrm{mL}$ ), the high perioperative CEA ratio group showed a worse survival rate than the low perioperative CEA ratio group $(33.3 \%$ vs. $75.0 \%, P=0.036)$. In the multivariate analysis, perioperative CEA ratio $(P=0.046)$, age $(\mathrm{P}=0.034)$, and venous invasion $(\mathrm{P}=0.015)$ were independent prognostic factors for survival.

Conclusion: The perioperative CEA ratio is a prognostic indicator for stage II colorectal cancer. Patients with normal preoperative serum CEA levels might also be considered for adjuvant therapy if their perioperative CEA ratios are higher than 0.5 .

Keywords: Adjuvant chemotherapy; Carcinoembryonic antigen; Neoplasm staging; Colorectal neoplasms; Prognosis

\section{INTRODUCTION}

Colorectal cancer is the fourth leading cause of death from cancer in Korea, with a crude mortality rate of $16.4 / 100,000$ [1]. Although the age-standardized incidence rate of colorectal cancer decreased from 2011 to 2014, it is still the third most frequently diagnosed

Received: August 27, 2017 - Accepted: October 2, 2017

Correspondence to: Byung-Noe Bae, M.D.

Department of Surgery, Inje University Sanggye Paik Hospital, Inje University College of Medicine, 1342 Dongil-ro, Nowon-gu, Seoul 01757, Korea Tel: +82-2-950-1017, Fax: +82-2-933-9389, E-mail: bnbae@paik.ac.kr ORCID code: https://orcid.org/0000-0002-5542-5626

\section{(c) 2018 The Korean Society of Coloproctology}

This is an open-access article distributed under the terms of the Creative Commons Attribution NonCommercial License (http://creativecommons.org/licenses/by-nc/4.0) which permits unrestricted noncommercial use, distribution, and reproduction in any medium, provided the original work is properly cited. cancer. The standardized treatment for nonmetastatic colorectal cancer is the radical resection of the tumor lesion. In patients with stage III (node-positive) disease, adjuvant chemotherapy is a routine therapy, and the benefits of chemotherapy have been clearly demonstrated [2]. The administration of chemotherapy in patients with stage II colorectal cancer (node-negative) remains controversial, but those with risk factors for recurrence are recommended for adjuvant chemotherapy [3].

Carcinoembryonic antigen (CEA) is one of the most readily accessible tumor markers for colorectal cancer. Increased preoperative serum CEA levels are related with an increased risk of recurrence and poor prognosis [4-6]. However, in 2006, the American Society of Clinical Oncology (ASCO) concluded that the evidence for using preoperative CEA levels as guidance for adjuvant chemotherapy was insufficient [7]. As studies on CEA have progressed, Lin et al. [8] reported that high early postoperative CEA levels are 
associated with early relapse of CRC and that early postoperative CEA values should surpass preoperative CEA values as a prognostic indicator. Others have confirmed the perioperative serum CEA change as a useful prognostic factor in patients with colorectal cancer [9-11].

Several recent studies have suggested that the ratio of preoperative to postoperative serum CEA is an independent predictor of OS for patients with colorectal cancer. The aim of this study was to evaluate whether the perioperative CEA ratio could be used as a determinant for adjuvant therapy after curative surgery on patients with stage II colorectal cancer.

\section{METHODS}

A total of 146 patients with stage II colorectal cancer who had undergone radical surgery between 2010 and 2013 at Inje University Sanggye Paik Hospital were analyzed retrospectively. TNM pathologic stage II disease was diagnosed according to the AJCC Cancer Staging Manual 7th edition [12]. We excluded patients without records of either preoperative or postoperative serum CEA levels and patients who had previous histories of surgical resection for colorectal cancer. Thus, 119 patients were enrolled in this study. The study was approved by the Institutional Review Board of Inje University Sanggye Paik Hospital and the informed consent was waived.

As a routine practice, we obtain serum CEA levels during the preoperative period and on the seventh postoperative day (median). Quantitative determinations of serum CEA were performed using enzyme immunoassays (ADVIA Centaur Systems, Siemens Healthcare Diagnostics Inc., Tarrytown, NY, USA). The normal serum CEA range was defined as below $5 \mathrm{ng} / \mathrm{mL}$. The perioperative CEA ratio was calculated as postoperative/preoperative serum CEA level, and the patients were grouped according to the perioperative CEA ratio: high ratio $(\geq 0.5)$ and low ratio $(<0.5)$.

Adjuvant chemotherapy was given to all except six patients. A total of 29 patients received intravenous chemotherapy based on 5-fluorouracil. The remaining patients received oral chemotherapy, including 48 patients treated with UFT (tegafur-uracil), 30 patients treated with doxifluridine (5'-deoxy-5-fluorouridine), and 6 patients treated with capecitabine. The expenses for oral chemotherapy are covered by the National Health Insurance Service in Korea; consequently, many patients had received oral chemotherapy. Six of the rectal cancer patients included in the study received preoperative chemoradiotherapy.

The patients were monitored at 3-month intervals for 2 years, at 6-month intervals for the next 3 years, and annually thereafter. History taking, physical examination, and serum CEA assays were performed at each visit. Patients underwent chest computed tomography (CT) and abdominopelvic CT every 6 months, and surveillance colonoscopy was performed a year after surgery and then biannually.

Statistical analyses were performed using IBM SPSS Statistics
Table 1. Demographics of the patients with stage II colorectal cancer $(\mathrm{n}=119)$

\begin{tabular}{lc}
\hline Variable & Value \\
\hline Age (yr) & $71(39-86)$ \\
Median (range) & $56(47.1)$ \\
$<70$ & $63(52.9)$ \\
$\geq 70$ & \\
Sex & $69(58)$ \\
Male & $50(42)$ \\
Female & \\
Serum CEA level (ng/mL) & \\
Preoperative & $2.52(0.5-530.80)$ \\
Median (range) & $85(71.4)$ \\
$<5$ & $34(28.6)$ \\
$\geq 5$ & \\
Perioperative ratio ${ }^{\text {a }}$ & \\
Median (range) & $0.5495(0.02-1.80)$ \\
$<0.5$ & $53(44.5)$ \\
$\geq 0.5$ & $66(55.5)$ \\
Postoperative & \\
Median (range) & $1.49(0.5-60.73)$ \\
$<5$ & $110(92.4)$ \\
$\geq 5$ & $9(7.6)$ \\
\hline
\end{tabular}

Histologic differentiation

Well

$12(10.1)$

Moderately

93 (78.2)

Poorly

$7(5.9)$

Mucinous adenocarcinoma

$7(5.9)$

Lymphatic invasion

Absent

59 (49.6)

Present

$60(50.4)$

Venous invasion

$\begin{array}{cc}\text { Absent } & 92(77.3) \\ \text { Present } & 26(21.8) \\ \text { Missing } & 1(0.8)\end{array}$

Perineural invasion

$\begin{array}{ll}\text { Absent } & 83(69.7) \\ \text { Present } & 11(9.2) \\ \text { Missing } & 25(21)\end{array}$

T stage (depth of invasion)

T3

$98(82.4)$

T4

$21(17.6)$ 
Table 1. Continued

\begin{tabular}{lc}
\hline Variable & Value \\
\hline No. of retrieved LNs & $21(3-19)$ \\
Median (range) & $14(11.8)$ \\
$<12$ & $105(88.2)$ \\
$\geq 12$ & \\
Endoscopic finding & $58(48.7)$ \\
Passing & $29(24.4)$ \\
Obstruction/stent & $32(26.9)$ \\
Missing & \\
No. of lesions & $111(93.3)$ \\
Single & $8(6.7)$ \\
Double (synchronous) & \\
Location of the tumor & $34(28.6)$ \\
Right colon & $75(63)$ \\
Left colon & $10(8.4)$ \\
Rectum
\end{tabular}

Values are presented as median (range) or number (\%).

CEA, carcinoembryonic antigen; LN, lymph node.

aPostoperative serum CEA level/preoperative serum CEA level.

ver. 24.0 (IBM Co., Armonk, NY, USA). Survival rates were estimated by using the Kaplan-Meier method, and univariate analyses of the significance of prognostic factors were evaluated by using the log-rank test. A multivariate analysis of factors associated with survival rates was performed using the Cox proportional hazards model with the backward stepwise (likelihood ratio) method. P-values $<0.05$ were considered statistically significant.

\section{RESULTS}

The clinical characteristics of the patients enrolled in this study are presented in Table 1. The median preoperative serum CEA level, postoperative serum CEA level, and perioperative CEA ratio were $2.52 \mathrm{ng} / \mathrm{mL}(0.5-530.80 \mathrm{ng} / \mathrm{mL}), 1.49 \mathrm{ng} / \mathrm{mL}(0.5-60.73$ $\mathrm{ng} / \mathrm{mL}$ ), and $0.5495(0.02-1.80)$, respectively. Out of 119 patients, 34 patients (28.6\%) had high preoperative CEA levels $(\geq 5 \mathrm{ng} / \mathrm{mL})$ whereas $85(71.4 \%)$ had normal preoperative CEA levels $(<5 \mathrm{ng} /$ $\mathrm{mL}$ ). A total of 66 patients (55.5\%) were placed in the high perioperative CEA ratio $(\geq 0.5 \mathrm{ng} / \mathrm{mL}$ ) group while 53 patients (44.5\%) were placed in the low perioperative CEA ratio $(<0.5 \mathrm{ng} / \mathrm{mL})$ group. The median age was 71 years (39-86 years), with 63 patients (52.9\%) being older than 70 .

On the univariate analyses (Table 2), the OS was longer in patients with low perioperative CEA ratios $(\mathrm{P}=0.033)$, age $<70(\mathrm{P}=$ $0.004)$, and no history of venous invasion $(\mathrm{P}=0.012)$. The patients with better tumor differentiation grades showed a reliable trend $(\mathrm{P}=0.092)$ toward longer survival. The multivariate analysis (Table 3) was performed on the significant factors $(\mathrm{P}<0.05)$ of
Table 2. Univariate analyses for independent predictors of overall survival (OS) $(\mathrm{n}=119)$

\begin{tabular}{|c|c|c|}
\hline Variable & $\mathrm{OS}^{\mathrm{b}}(\%)$ & P-value \\
\hline \multicolumn{3}{|l|}{ Preoperative CEA level (ng/mL) } \\
\hline$<5$ & 80.0 & 0.097 \\
\hline$\geq 5$ & 67.6 & \\
\hline \multicolumn{3}{|l|}{ Perioperative CEA ratio ${ }^{\mathrm{a}}$} \\
\hline$<0.5$ & 86.8 & 0.033 \\
\hline$\geq 0.5$ & 68.2 & \\
\hline \multicolumn{3}{|l|}{ Postoperative CEA level (ng/mL) } \\
\hline$<5$ & 76.4 & 0.935 \\
\hline$\geq 5$ & 77.8 & \\
\hline \multicolumn{3}{|l|}{ Age (yr) } \\
\hline$<70$ & 87.5 & 0.004 \\
\hline$\geq 70$ & 66.7 & \\
\hline \multicolumn{3}{|l|}{ Sex } \\
\hline Male & 71.0 & 0.127 \\
\hline Female & 84.0 & \\
\hline \multicolumn{3}{|l|}{ Histologic differentiation } \\
\hline Well & 100.0 & 0.092 \\
\hline Moderately & 74.2 & \\
\hline Poorly & 57.1 & \\
\hline Mucinous adenocarcinoma & 85.7 & \\
\hline \multicolumn{3}{|l|}{ No. of retrieved LNs } \\
\hline$<12$ & 57.1 & 0.087 \\
\hline$\geq 12$ & 79.0 & \\
\hline \multicolumn{3}{|l|}{ Lymphatic invasion } \\
\hline Absent & 83.1 & 0.074 \\
\hline Present & 70.0 & \\
\hline \multicolumn{3}{|l|}{ Venous invasion } \\
\hline Absent & 82.6 & 0.012 \\
\hline Present & 57.7 & \\
\hline \multicolumn{3}{|l|}{ Perineural invasion } \\
\hline Absent & 79.5 & 0.172 \\
\hline Present & 63.6 & \\
\hline \multicolumn{3}{|l|}{ T stage (depth of invasion) } \\
\hline T3 & 76.5 & 0.754 \\
\hline $\mathrm{T} 4$ & 76.2 & \\
\hline \multicolumn{3}{|l|}{ Endoscopic finding } \\
\hline Passing & 79.3 & 0.166 \\
\hline Obstruction/stent & 65.5 & \\
\hline \multicolumn{3}{|l|}{ No. of lesions } \\
\hline Single & 76.6 & 0.839 \\
\hline Double (synchronous) & 75.0 & \\
\hline \multicolumn{3}{|l|}{ Location of the tumor } \\
\hline Right colon & 88.2 & 0.203 \\
\hline Left colon & 72.0 & \\
\hline Rectum & 70.0 & \\
\hline
\end{tabular}

CEA, carcinoembryonic antigen; OS, overall survival.

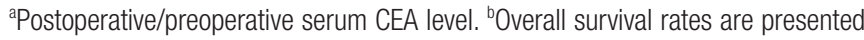
as percentages. 
Table 3. Multivariate analyses for independent predictors of overall survival

\begin{tabular}{lccc}
\hline Variable & HR & $95 \%$ Cl & P-value \\
\hline Perioperative CEA ratio ${ }^{\mathrm{a}},<0.5$ vs. $\geq 0.5$ & 2.460 & $1.017-5.946$ & 0.046 \\
Venous invasion, absent vs. present & 2.678 & $1.210-5.928$ & 0.015 \\
Age $(\mathrm{yr}),<70$ vs. $\geq 70$ & 2.773 & $1.079-7.127$ & 0.034 \\
\hline
\end{tabular}

$\mathrm{HR}$, hazard ratio; $\mathrm{Cl}$, confidence interval; $\mathrm{CEA}$, carcinoembryonic antigen. aPostoperative/preoperative serum CEA level.

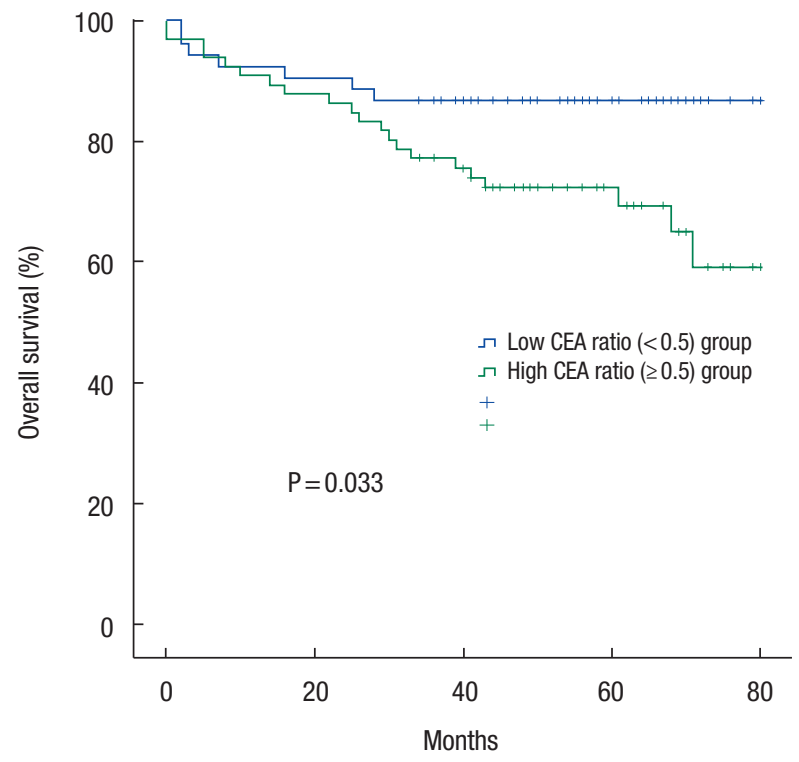

Fig. 1. Overall survival rates of patients based on perioperative carcinoembryonic antigen (CEA) ratio.

the univariate analyses. Similarly, age, venous invasion, and perioperative CEA ratio were independent prognostic factors for OS. Fig. 1 depicts the OS curves obtained by using the Kaplan-Meier method and the log-rank test value.

On the univariate analysis, perineural invasion $(\mathrm{P}=0.021)$ was the only significant prognostic factor for disease-free survival (DFS). Patients with low perioperative CEA ratios were not associated with a better DFS rate compared to patients with high perioperative CEA ratios $(84.9 \%$ vs. $84.8 \%, \mathrm{P}=0.962)$. The systemic and the locoregional recurrence rates for the high perioperative CEA ratio group vs. the low CEA perioperative ratio group were $11.3 \%$ vs. $13.6 \%(\mathrm{P}=0.705)$ and $5.7 \%$ vs. $4.5 \%(\mathrm{P}=0.782)$.

In patients with normal preoperative CEA levels $(<5 \mathrm{ng} / \mathrm{mL})$, the OS and the DFS for the high perioperative CEA ratio group $(\mathrm{n}=$ 60 ) vs. the low perioperative CEA ratio group $(\mathrm{n}=25)$ were $71.7 \%$ vs. $100.0 \%(\mathrm{P}=0.007)$ (Table 4$)$ and $86.7 \%$ vs. $88.0 \%(\mathrm{P}=0.786)$. In patients with high preoperative CEA levels ( $\geq 5 \mathrm{ng} / \mathrm{mL}$ ), the OS and the DFS for the high perioperative CEA ratio group $(n=6)$ vs. the low perioperative CEA ratio group $(n=28)$ were $33.3 \%$ vs. $75.0 \%$ $(\mathrm{P}=0.036)$ (Table 4$)$ and $66.7 \%$ vs. $82.1 \%(\mathrm{P}=0.184)$. Fig. 2 de-

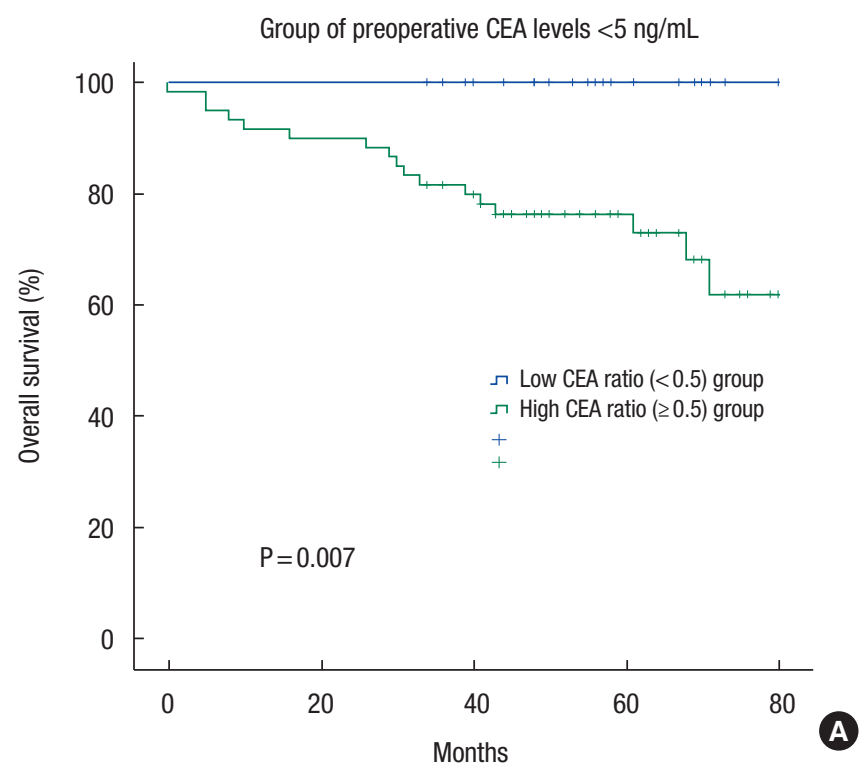

Group of preoperative CEA levels $\geq 5 \mathrm{ng} / \mathrm{mL}$

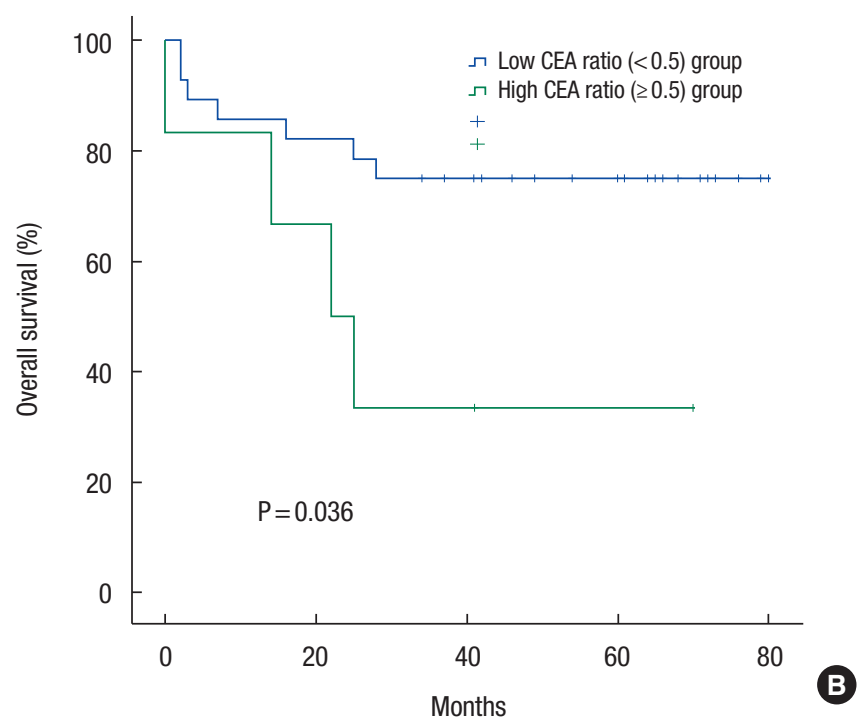

Fig. 2. Overall survival curves of patients based on perioperative carcinoembryonic antigen (CEA) ratio in the groups with preoperative CEA levels of $<5 \mathrm{ng} / \mathrm{mL}$ (A) and $\geq 5 \mathrm{ng} / \mathrm{mL}$ (B).

picts the OS curves of the patients based on the perioperative CEA ratio in the groups with normal and high preoperative CEA levels.

\section{DISCUSSION}

In stage II colorectal cancer, a survival benefit has not been demonstrated for adjuvant chemotherapy [13]. However, the administration of adjuvant chemotherapy should be considered if high risk factors are present. The ASCO, the National Comprehensive Cancer Network, and the European Society for Medical Oncology 
Table 4. Univariate analyses for independent predictors of overall survival (OS) according to preoperative carcinoembryonic antigen (CEA) level

\begin{tabular}{|c|c|c|c|c|c|c|}
\hline \multirow{3}{*}{ Variable } & \multicolumn{6}{|c|}{ Preoperative CEA level } \\
\hline & \multicolumn{3}{|c|}{$<5 \mathrm{ng} / \mathrm{mL}(\mathrm{n}=85)$} & \multicolumn{3}{|c|}{$\geq 5 \mathrm{ng} / \mathrm{mL}(\mathrm{n}=34)$} \\
\hline & Total $N^{b}$ & $\mathrm{OS}^{\mathrm{c}}(\%)$ & P-value & Total N & OS (\%) & P-value \\
\hline \multicolumn{7}{|l|}{ Perioperative CEA ratio ${ }^{\mathrm{a}}$} \\
\hline$<0.5$ & 25 & 100 & 0.007 & 28 & 75.0 & 0.036 \\
\hline$\geq 0.5$ & 60 & 71.7 & & 6 & 33.3 & \\
\hline \multicolumn{7}{|l|}{ Postoperative CEA level (ng/mL) } \\
\hline$<5$ & 85 & 80.0 & - & 25 & 64.0 & 0.493 \\
\hline$\geq 5$ & 0 & - & & 9 & 77.8 & \\
\hline \multicolumn{7}{|l|}{ Age (yr) } \\
\hline$<70$ & 43 & 88.4 & 0.017 & 13 & 84.6 & 0.121 \\
\hline$\geq 70$ & 42 & 71.4 & & 21 & 57.1 & \\
\hline \multicolumn{7}{|l|}{ Sex } \\
\hline Male & 50 & 74.0 & 0.136 & 19 & 63.2 & 0.477 \\
\hline Female & 35 & 88.6 & & 15 & 73.3 & \\
\hline \multicolumn{7}{|l|}{ Histologic differentiation } \\
\hline Well & 9 & 100 & 0.160 & 3 & 100 & 0.476 \\
\hline Moderately & 66 & 77.3 & & 27 & 66.7 & \\
\hline Poorly & 6 & 66.7 & & 1 & 0.0 & \\
\hline Mucinous adenocarcinoma & 4 & 100 & & 3 & 66.7 & \\
\hline \multicolumn{7}{|l|}{ No. of retrieved LNs } \\
\hline$<12$ & 10 & 50.0 & 0.003 & 4 & 75.0 & 0.711 \\
\hline$\geq 12$ & 75 & 84.0 & & 30 & 66.7 & \\
\hline \multicolumn{7}{|l|}{ Lymphatic invasion } \\
\hline Absent & 43 & 86.0 & 0.133 & 16 & 75.0 & 0.348 \\
\hline Present & 42 & 73.8 & & 18 & 61.1 & \\
\hline \multicolumn{7}{|l|}{ Venous invasion } \\
\hline Absent & 69 & 85.5 & 0.075 & 23 & 73.9 & 0.229 \\
\hline Present & 15 & 60.0 & & 11 & 54.5 & \\
\hline \multicolumn{7}{|l|}{ Perineural invasion } \\
\hline Absent & 61 & 83.6 & 0.383 & 22 & 68.2 & 0.371 \\
\hline Present & 7 & 71.4 & & 4 & 50.0 & \\
\hline \multicolumn{7}{|l|}{ T stage (depth of invasion) } \\
\hline $\mathrm{T} 3$ & 74 & 79.7 & 0.999 & 24 & 66.7 & 0.970 \\
\hline T4 & 11 & 81.8 & & 10 & 70.0 & \\
\hline \multicolumn{7}{|l|}{ Endoscopic finding } \\
\hline Passing & 45 & 80.0 & 0.160 & 13 & 76.9 & 0.607 \\
\hline Obstruction/stent & 20 & 65.0 & & 9 & 66.7 & \\
\hline \multicolumn{7}{|l|}{ No. of lesions } \\
\hline Single & 81 & 80.2 & 0.758 & 30 & 66.7 & 0.756 \\
\hline Double (synchronous) & 4 & 75.0 & & 4 & 75.0 & \\
\hline \multicolumn{7}{|l|}{ Location of the tumor } \\
\hline Right colon & 26 & 92.3 & 0.164 & 8 & 75.0 & 0.572 \\
\hline Left colon & 52 & 73.1 & & 23 & 69.6 & \\
\hline Rectum & 7 & 85.7 & & 3 & 33.3 & \\
\hline
\end{tabular}

LN, lymph node.

${ }^{\text {aP }}$ ostoperative/preoperative serum CEA level. ${ }^{\text {}}$ Total number of patients. ${ }^{~}$ Overall survival rates are presented as percentages. 
have suggested several high-risk factors, which include fewer than 12 lymph nodes sampled, poorly differentiated histology, colonic obstruction or perforation, perineural, vascular, or lymphatic invasion, T4 lesions, close or positive margins, and mismatch repair status $[7,14]$. Although abundant studies suggest that preoperative CEA is an independent risk factor for survival, no expert panel has accepted elevated preoperative CEA levels as a determinant for adjuvant chemotherapy in patients with stage II colorectal cancer.

In the present study, we observed the following risk factors for patients with stage II colorectal cancer: the presence of lymphatic invasion, age $\geq 70$ years, and high perioperative CEA ratio $(\geq 0.5$ $\mathrm{ng} / \mathrm{mL}$ ). However, the preoperative CEA level for OS failed to reach statistical significance, suggesting that a high preoperative CEA level itself lacks the power to discriminate the poor prognostic group in patients with stage II colorectal cancer. Indeed, many researchers have reported results supporting this finding. Moertel et al. [15] stated that CEA was not significantly associated with survival among Dukes' A and B lesions, and other researchers have insisted that the parameter of CEA should reflect postoperative CEA levels [8]. The perioperative CEA ratio we have suggested has strength, in that it covers both preoperative and postoperative CEA levels. The estimated half-life of serum CEA is 3 to 5 days, and if a successful surgical resection is done, high levels of CEA should return to the normal range within 2 weeks to 1 month [16, 17]. Therefore, the perioperative ratio may reflect how radically the tumor has been resected. Several researchers have suggested that perioperative serum CEA changes in the preoperative and early postoperative periods are predictive of recurrence and prognosis in patients with colorectal cancer [9-11, 18, 19].

The major finding of our study was that the low perioperative CEA ratio $(<0.5 \mathrm{ng} / \mathrm{mL})$ group showed better prognosis than the high perioperative CEA ratio ( $\geq 0.5 \mathrm{ng} / \mathrm{mL})$ group; that is to say, a decrease in the serum CEA level of over $50 \%$ after radical surgery was related to better OS. We have set the reference point for the perioperative CEA ratio as $0.5 \mathrm{ng} / \mathrm{mL}$ because previous studies demonstrated that a value close to ' $50 \%$ decreased rate' of perioperative serum CEA had statistical significance in determining OS $[10,11]$. According to these studies, normalization of the early postoperative CEA level and a decreased rate of perioperative CEA could be used as prognostic factors for patients who have elevated preoperative CEA levels $[10,11]$. Similarly, we observed that patients with preoperative CEA levels $\geq 5 \mathrm{ng} / \mathrm{mL}$ had better survival rates if their perioperative CEA ratios were less than $0.5 \mathrm{ng} / \mathrm{mL}$.

An exclusive finding in our study was that the perioperative CEA ratio was associated with survival difference regardless of preoperative serum CEA level. Among the patients with normal preoperative CEA levels, the OS of the low perioperative CEA ratio group was higher than that of the high perioperative CEA ratio group. The conventional view of tumor markers is that when their levels are in the normal range, the risk of recurrence is assumed to be low. However, the CEA level is a marker of considerable individuality, which means that the usual cut-off limits are inappropriate for detecting unusual results in a particular subject [20, 21]. Instead, serial measurements from an individual form a better basis for early detection of relapse [22]. Therefore, based on our study and those of others, a perioperative change in serum CEA should be calculated even if the preoperative and the postoperative CEA levels are within the normal ranges.

As mentioned previously, the present study suggested the perioperative CEA ratio as an independent prognostic factor for OS. However, in terms of the possible prognostic factors for DFS, the perioperative CEA ratio was not significantly related to the survival rate. In addition, the univariate analysis among the patients with normal preoperative CEA levels (Table 4) proved that a number of retrieved lymph nodes $<12$, age $\geq 70$ years, and high perioperative CEA ratio $(\geq 0.5 \mathrm{ng} / \mathrm{mL})$ were poor prognostic factors. However, when a multivariate analysis was performed, age $\geq 70$ years $(\mathrm{P}=0.018$; hazard ratio, 3.425; 95\% confidence interval, 1.235-9.501) was the only significant factor whereas the number of retrieved lymph nodes $(\mathrm{P}=0.084)$ and the perioperative CEA ratio $(\mathrm{P}=0.959)$ lost their significance. This may limit the validity of the conclusions of the present study. In both groups, normal and high preoperative CEA levels, patients with T4 stage showed better survival rate than patients with T3 stage (Table 4). The small number of samples might be cause of the outcome, which is different from general expectation. Further research on a large population of patients is necessary to investigate the perioperative CEA ratio and prognostic factors.

In conclusion, the perioperative CEA ratio is a prognostic indicator for patients with stage II colorectal cancer. Our study confirmed that the perioperative CEA ratio could be a better prognostic factor than the preoperative and the postoperative CEA levels. Patients with normal preoperative serum CEA levels should also be monitored thoroughly and considered for adjuvant therapy if their perioperative CEA ratios are higher than $0.5 \mathrm{ng} / \mathrm{mL}$.

\section{CONFLICT OF INTEREST}

No potential conflict of interest relevant to this article was reported.

\section{REFERENCES}

1. Son M, Yun JW. Cancer mortality projections in Korea up to 2032. J Korean Med Sci 2016;31:892-901.

2. NIH consensus conference. Adjuvant therapy for patients with colon and rectal cancer. JAMA 1990;264:1444-50.

3. Påhlman LA, Hohenberger WM, Matzel K, Sugihara K, Quirke P, Glimelius B. Should the benefit of adjuvant chemotherapy in colon cancer be re-evaluated? J Clin Oncol 2016;34:1297-9.

4. Carriquiry LA, Piñeyro A. Should carcinoembryonic antigen be used in the management of patients with colorectal cancer? Dis Colon Rectum 1999;42:921-9.

5. Harrison LE, Guillem JG, Paty P, Cohen AM. Preoperative carcinoembryonic antigen predicts outcomes in node-negative colon 
cancer patients: a multivariate analysis of 572 patients. J Am Coll Surg 1997;185:55-9.

6. Chu DZ, Erickson CA, Russell MP, Thompson C, Lang NP, Broadwater RJ, et al. Prognostic significance of carcinoembryonic antigen in colorectal carcinoma. Serum levels before and after resection and before recurrence. Arch Surg 1991;126:314-6.

7. Benson AB 3rd, Schrag D, Somerfield MR, Cohen AM, Figueredo AT, Flynn PJ, et al. American Society of Clinical Oncology recommendations on adjuvant chemotherapy for stage II colon cancer. J Clin Oncol 2004;22:3408-19.

8. Lin JK, Lin CC, Yang SH, Wang HS, Jiang JK, Lan YT, et al. Early postoperative CEA level is a better prognostic indicator than is preoperative CEA level in predicting prognosis of patients with curable colorectal cancer. Int J Colorectal Dis 2011;26:1135-41.

9. Park YA, Lee KY, Kim NK, Baik SH, Sohn SK, Cho CW. Prognostic effect of perioperative change of serum carcinoembryonic antigen level: a useful tool for detection of systemic recurrence in rectal cancer. Ann Surg Oncol 2006;13:645-50.

10. Jung TD, Yoo JH, Lee MJ, Park HK, Shin JH, An MS, et al. Prognostic significance of the decreased rate of perioperative serum carcinoembryonic antigen level in the patients with colon cancer after a curative resection. Ann Coloproctol 2013;29:115-22.

11. Lee WS, Baek JH, Kim KK, Park YH. The prognostic significant of percentage drop in serum CEA post curative resection for colon cancer. Surg Oncol 2012;21:45-51.

12. Edge SB, Compton CC. The American Joint Committee on Cancer: the 7th edition of the AJCC cancer staging manual and the future of TNM. Ann Surg Oncol 2010;17:1471-4.

13. Tournigand C, André T, Bonnetain F, Chibaudel B, Lledo G, Hickish $\mathrm{T}$, et al. Adjuvant therapy with fluorouracil and oxaliplatin in stage II and elderly patients (between ages 70 and 75 years) with colon cancer: subgroup analyses of the Multicenter International Study of Oxaliplatin, Fluorouracil, and Leucovorin in the Adju- vant Treatment of Colon Cancer trial. J Clin Oncol 2012;30:335360 .

14. Labianca R, Nordlinger B, Beretta GD, Brouquet A, Cervantes A; ESMO Guidelines Working Group. Primary colon cancer: ESMO Clinical Practice Guidelines for diagnosis, adjuvant treatment and follow-up. Ann Oncol 2010;21 Suppl 5:v70-7.

15. Moertel CG, O’Fallon JR, Go VL, O'Connell MJ, Thynne GS. The preoperative carcinoembryonic antigen test in the diagnosis, staging, and prognosis of colorectal cancer. Cancer 1986;58:603-10.

16. Rapellino M, Piantino P, Pecchio F, Ruffini E, Cavallo A, Scappaticci E, et al. Disappearance curves of tumor markers after radical surgery. Int J Biol Markers 1994;9:33-7.

17. Holyoke ED, Chu TM, Murphy GP. CEA as a monitor of gastrointestinal malignancy. Cancer 1975;35:830-6.

18. Hotta T, Takifuji K, Yokoyama S, Matsuda K, Oku Y, Nasu T, et al. Impact of the post/preoperative serum CEA ratio on the survival of patients with rectal cancer. Surg Today 2014;44:2106-15.

19. Sun Z, Wang F, Zhou Q, Yang S, Sun X, Wang G, et al. Pre-operative to post-operative serum carcinoembryonic antigen ratio is a prognostic indicator in colorectal cancer. Oncotarget 2017;8:5467282.

20. Erden G, Barazi AO, Tezcan G, Yildirimkaya MM. Biological variation and reference change values of CA 19-9, CEA, AFP in serum of healthy individuals. Scand J Clin Lab Invest 2008;68:212-8.

21. Sölétormos G, Schiøler V, Nielsen D, Skovsgaard T, Dombernowsky P. Interpretation of results for tumor markers on the basis of analytical imprecision and biological variation. Clin Chem 1993;39: 2077-83.

22. Tuxen MK, Sölétormos G, Petersen PH, Schioler V, Dombernowsky P. Assessment of biological variation and analytical imprecision of CA 125, CEA, and TPA in relation to monitoring of ovarian cancer. Gynecol Oncol 1999;74:12-22. 